\title{
Intervención en el Retablo de los Evangelistas de la Catedral de Sevilla. Convenio de colaboración
}

Tras la presentación de un Proyecto de Intervención realizado por técnicos del Instituto Andaluz del Patrimonio Histórico, se acuerda un convenio de colaboración entre la Consejería de Cultura de la Junta de Andalucía y el Cabildo de la Catedral de Sevilla para la conservación y restauración del Retablo de los Evangelistas, situado en la Capilla del mismo nombre en la catedral hispalense.

El retablo, cuya estructura portante se sustituyó en el siglo XVIII por una de estilo neoclásico, está compuesto por diez pinturas sobre tabla realizadas por Hernando de Esturmio entre $\mathbf{I} 553$ y $\mathbf{I} 555$.

La intervención de este retablo comprende los tratamientos de conservación - restauración tanto de la arquitectura lignaria como de siete de las diez pinturas que lo compone: "San Juan Bautista, San Antón y San Sebastián" calle central del banco; "Misa de San Gregorio" calle central del primer cuerpo; "San Marco" lateral derecho del primer cuerpo; "San Mateo" lateral izquierdo del segundo cuerpo; "Resurrección de Cristo" calle central del segundo cuerpo; "San Juan" lateral derecho del segundo cuerpo y "Espíritu
Santo" en el ático. Ya en su momento, se intervino sobre las dos pinturas laterales del banco y la situada en el lateral izquierdo del primer cuerpo.

Una vez aprobado el convenio, se iniciará el proyecto que comprende tres anualidades como plazo máximo para la ejecución del mismo. El presupuesto de la ejecución material asciende a la cantidad de 21.292 .516 pesetas (IVA incluido) del cual dos terceras partes será financiado por la Catedral y la tercera parte restante por la Consejería de Cultura de la Junta de Andalucía.

Teniendo en cuenta el delicado estado de conservación que presentan principalmente las pinturas y que la estabilidad del retablo depende en gran medida del sistema estructural basado en la transmisión de cargas, la opción de desmontar en varias fases para su intervención no sería lo más aconsejable al poder crear tensiones y desestabilización. Es por ello importante destacar la conveniencia de realizar una actuación global de los elementos muebles e inmuebles. A su vez, esta actuación va a agilizar el proceso de intervención, teniendo en cuenta que el conjunto de

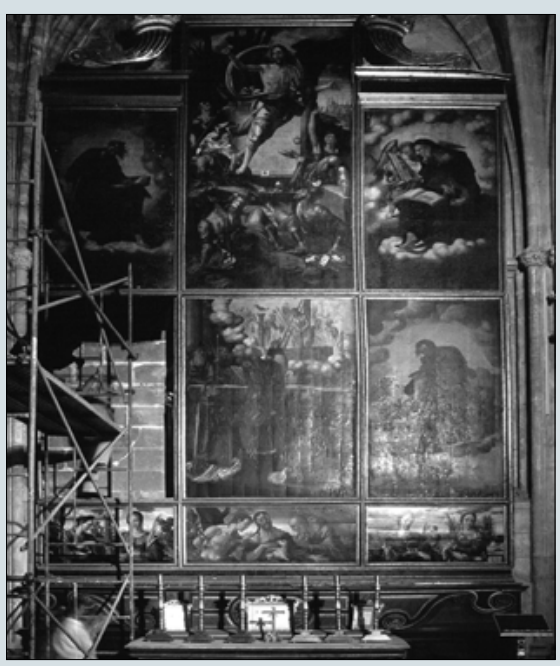

fases que marcan su desarrollo podría realizarse simultáneamente en todas las piezas.

Se plantea además, en este proyecto, debido al deterioro derivado de la propia constitución estructural, la sustitución del antiguo sistema creando una nueva estructura autoportante realizada con elementos metálicos y adelantando el retablo, separándolo del muro, garantizando así unas condiciones más óptimas en su conservación y facilitando la accesibilidad al reverso, necesaria para realizar labores de mantenimiento, inspección y futuras intervenciones.

Rocío Magdaleno Granja Departamento de Tratamiento del IAPH

\section{Reeditada la Guía práctica para la interpretación del patrimonio}

La Consejería de Cultura de la Junta de Andalucía ha reeditado, en colaboración con la Empresa Publica Medioambiental Tragsa, el libro Guía práctica para la interpretación del patrimonio: el arte de acercar el legado natural y cultural al público visitante, dada la gran demanda existente en los mercados español e iberoamericano.

Esta tirada, al igual que la primera, realizada en 1998 y rápidamente agotada, consta de 2.000 ejemplares, que pueden adquirirse a través de la Empresa Pública de Gestión de Programas Culturales:

C/ Levíes, 17

41004 Sevilla

Tel.: 955036700

Fax: 955036687

Web: www.epgpc.com
Merece la pena recordar que esta obra es la primera revisión exhaustiva en lengua castellana acerca de los métodos para presentar el patrimonio natural y cultural al público visitante. En el mismo se tratan aspectos teóricos esenciales para llevar a cabo trabajos de comunicación con el público, exponiendo aspectos profesionales de la disciplina interpretativa.

El trabajo se articula en catorce capítulos, en los que se analiza el concepto de interpretación del patrimonio como instrumento específico para la comunicación con el público visitante. El autor, Jorge Morales, pone especial hincapié en la necesidad de planificar la interpretación y en los distintos medios interpretativos. Asimismo, propone una serie de sugerencias prácticas sobre itinerarios, señalización, publicidad, etc.
Finalmente, se recoge una selección bibliográfica sobre el tema en cuestión.

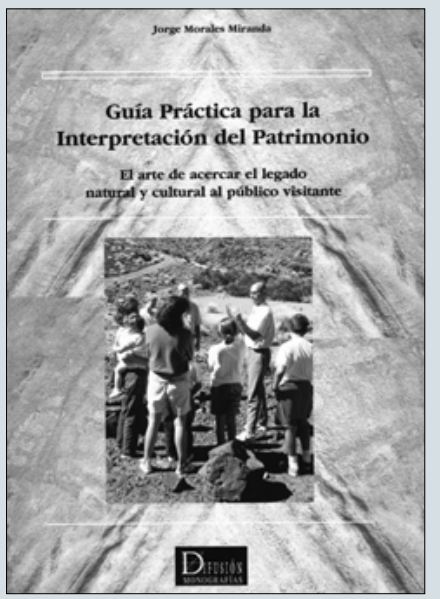

